\title{
Feto-maternal outcome of oligohydramnios in tertiary care hospital
}

\author{
Shetal Prajapati, Sakina Johar*
}

Department of Obstetrics and gynaecology, PDU Medical College, Rajkot, Gujarat, India

Received: 19 July 2021

Accepted: 08 October 2021

\author{
*Correspondence: \\ Dr. Sakina Johar, \\ E-mail: dr.sakina.bootwala@gmail.com
}

Copyright: (c) the author(s), publisher and licensee Medip Academy. This is an open-access article distributed under the terms of the Creative Commons Attribution Non-Commercial License, which permits unrestricted non-commercial use, distribution, and reproduction in any medium, provided the original work is properly cited.

\begin{abstract}
Background: The importance of amniotic fluid volume as an indicator of fetal wellbeing has made its assessment an important part of antenatal fetal surveillance. Oligohydramnios complicates $0.5 \%$ to $8 \%$ of pregnancies and the prognosis for pregnancies complicated by oligohydramnios is dependent on the gestational age and the underlying aetiology. This study aims to determine the feto-maternal outcome of oligohydramnios in a tertiary care hospital.

Methods: In this study, we included 100 patients of oligohydramnios, with AFI $\leq 5 \mathrm{~cm}$ with a singleton pregnancy with intact membranes. The maternal outcome was accessed by mode of delivery and maternal complications and the neonatal outcome was studied by birth weight, APGAR score, NICU admission and perinatal mortality.

Results: PIH was the most common risk factor in $38 \%$ of cases followed by IUGR in $29 \%$, doppler changes in $24 \%$. The reduced diastolic flow was the most common abnormal doppler finding in the $23 \%$ abnormal doppler cases, from which $39 \%$ underwent caesarean section, $9 \%$ required NICU admission and $61 \%$ had neonatal death. 53\% delivered by caesarean section of which $13 \%$ had neonatal death. NICU admission is required in $64 \%$ of cases.

Conclusions: We conclude that oligohydramnios is a high-risk pregnancy and proper antepartum care, intensive fetal surveillance and intrapartum care are required in a patient with oligohydramnios. Every case of oligohydramnios needs careful antenatal evaluation, parental counselling, individualization, decisions regarding time and mode of delivery. Continuous intrapartum fetal monitoring and good neonatal care are necessary for a better perinatal outcome.
\end{abstract}

Keywords: Oligohydramnios, AFI, Feto-maternal outcome, IUGR, Perinatal mortality

\section{INTRODUCTION}

Amniotic fluid (AF) is the protective liquid contained by the amniotic sac of a gravid amniote. It provides temperature stability, cushioning and a necessary presence in collapsed airways to help stimulate lung development.

The importance of amniotic fluid volume as an indicator of fetal wellbeing has made its assessment an important part of antenatal fetal surveillance. Abnormalities such as meconium staining, congenital anomalies, growth retardation, dysmaturity and fetal asphyxia have been associated with reduced amniotic fluid volume. ${ }^{1-3}$

Amniotic fluid volume is the sum of inflow and outflow of fluid into amniotic space and as such reflects fetal fluid balance. The amniotic fluid volume at each week of pregnancy is variable. It increases from $20 \mathrm{ml}$ at 10 weeks to $770 \mathrm{ml}$ at 28 weeks, remains at a steady state till 39 weeks after which it decreases dramatically. The average amniotic fluid volume in 3rd trimester is $700-800 \mathrm{ml}$. Clinical assessment of amniotic fluid volume including bimanual palpation, symphysial-fundal height is unreliable. Diagnosis is usually done by ultrasound. Definition of increased or decreased amniotic fluid volume is based on sonographic criteria. Oligohydramnios is diagnosed when the ultrasonographic amniotic fluid index (AFI) is $\leq 5 \mathrm{~cm}$ or 5 th percentile, or a single deepest pocket of $<2 \mathrm{~cm}$. It is associated with a high risk-averse perinatal outcome like fetal distress, meconium staining, low APGAR and neonatal resuscitation, NICU admission. This 
assessment is a helpful tool in determining the risk of potentially adverse obstetric and perinatal outcomes.

The volume of the amniotic fluid decreases with increasing gestational age. The decrease in amniotic fluid volume is called oligohydramnios. ${ }^{4}$ The findings of oligohydramnios can be associated with increased risk of intrauterine growth retardation (IUGR), meconium aspiration syndrome, severe birth asphyxia, low APGAR scores and congenital abnormalities, premature rupture of membranes, uteroplacental insufficiency, post-dates. $^{5}$ Oligohydramnios increases maternal morbidity by increasing rates of induction and/ or operative interference. $^{6} \quad$ The sequel from long-standing oligohydramnios includes pulmonary hypoplasia, potter's syndrome, club foot, club hand and dislocation of the hip. It is found to be associated with a high incidence of maternal and perinatal morbidity and mortality.

During labor, the predominant mechanical function of amniotic fluid is to provide an aquatic cushion for the umbilical cord. Without this cushion, compression of the cord between the fetus and the uterine wall may occur during contractions or fetal movement, this cord compression causes severe fetal heart rate (FHR) decelerations which are associated with low APGAR scores and acidosis at birth, meconium staining, caesarean section for fetal distress.

With the help of amniotic fluid estimation by amniotic fluid Index (AFI) using the four-quadrant technique during transabdominal USG, as described by Phelan et al in $1997 .^{7}$ Better identification of fetuses at high risk is done. Increased elective caesarean deliveries are currently practised for better perinatal outcomes.

Oligohydramnios complicates $0.5 \%$ to $8 \%$ of pregnancies and the prognosis for pregnancies complicated by oligohydramnios is dependent on the gestational age and the underlying aetiology (Marino, 2004). ${ }^{8}$

In this study, we accessed maternal outcomes in the form of the mode of delivery: normal vaginal delivery (spontaneous or induced), instrumental vaginal delivery and caesarean section, in all patients of Oligohydramnios of different age groups and parity. We studied different causes of Oligohydramnios. Fetal surveillance was done by non-stress test (NST) and doppler study. The neonatal outcome was studied by IUGR, APGAR score, NICU admission, perinatal mortality and congenital anomalies.

\section{METHODS}

The present study is a prospective observational hospitalbased study carried out from September 2018 to September 2020 at the department of obstetrics and gynaecology, PDU medical college, Rajkot, Gujarat. During this period 100 patients in the third trimester of pregnancy with Oligohydramnios were selected randomly after satisfying inclusion and exclusion criteria. Ethical clearance was obtained for this study from the institution.

\section{Inclusion criteria}

Singleton pregnancy in the third trimester ( $\geq 28$ weeks). Pregnancy with intact membranes. AFI $\leq 5 \mathrm{~cm}$ in USG.

\section{Exclusion criteria}

Patient with multiple gestations. Patient with PROM. Polyhydramnios.

The study was conducted to observe the outcome of labor in the form of perinatal morbidity and maternal outcome in the form of vaginal or caesarean section deliveries.

A detailed history and examination were done. History about the patient's age, obstetric code, gestational age, menstrual history, obstetric history, associated complications in present pregnancy was noted. Symphysial-fundal height was measured in centimetres. Fetal movements and fetal heart rates were recorded serially. All required investigation: - Hemogram, Blood grouping and Rh typing, cell counts, BSL, TFT, VDRL, HIV, HBsAg, Ultrasound Doppler study, NST, urine routine and microscopy were done. Speculum and per vaginal examination were done to rule out draining per vaginum and confirmed intact membranes. After taking informed consent patients were treated. Iron, calcium, and multivitamin supplements were continued orally as before. AFI measurements were done. These women were followed till discharge.

Oligohydramnios was confirmed in all by measuring amniotic fluid index (AFI). Routine management in the form of rest left lateral position, oral and intravenous hydration and control of etiological factor (if present) were done.

Fetal surveillance was done by USG, a non-stress test (NST) and Doppler.

The decision of delivery by vaginal route or elective/ emergency LSCS was done as required. Some patients were already in labour and others were allowed to go into spontaneous labour or were induced to go into labour. If delivery is made by caesarean section, the indication was recorded.

A pre-designed study proforma was filled for each case.

Cases were then studied for the maternal and perinatal outcomes. The outcome of the baby was studied by birth weight, APGAR score, NICU admission or perinatal mortality.

The following outcomes were recorded: mode of delivery, meconium staining, APGAR score at 5 minutes, birth weight, NICU admissions. final outcome. 


\section{RESULTS}

Out of 100 patients recruited in the study maximum patients $(94 \%)$ were in the $20-30$ years age group. Out of this $94 \%$ of patients $48 \%$ were delivered vaginally and $52 \%$ were delivered by caesarean section. $1 \%$ of patients were less than 20 years of age which were delivered by caesarean section. $5 \%$ of patients were more than 30 years of age, of which $80 \%$ were patients delivered by caesarean section. The rate of caesarean was highest in patients of age group 20-30 years (Table 1).

Table 1: Relation between age and mode of delivery.

\begin{tabular}{|llll|}
\hline $\begin{array}{l}\text { Age in } \\
\text { years }\end{array}$ & $\begin{array}{l}\text { Vaginal } \\
\text { delivery }\end{array}$ & Caesarean & Total \\
\hline $\begin{array}{l}\text { Less than } \\
\mathbf{2 0}\end{array}$ & 0 & $01(100 \%)$ & $01(1 \%)$ \\
\hline $\mathbf{2 0 - 3 0}$ & $45(48 \%)$ & $49(52 \%)$ & $94(94 \%)$ \\
\hline $\begin{array}{l}\text { More than } \\
\mathbf{3 0}\end{array}$ & $01(20 \%)$ & $04(80 \%)$ & $05(5 \%)$ \\
\hline
\end{tabular}

Table 2: Incidence of gravida.

\begin{tabular}{|ll|}
\hline Gravida & No. of cases \\
\hline Primi & $50(50 \%)$ \\
\hline 2nd & $25(25 \%)$ \\
\hline 3rd & $17(17 \%)$ \\
\hline 4th & $04(4 \%)$ \\
\hline 5th & $01(1 \%)$ \\
\hline 6th & $03(3 \%)$ \\
\hline
\end{tabular}

Table 3: Mode of delivery.

\begin{tabular}{|ll|}
\hline Mode of delivery & No. of cases \\
\hline Induced vaginal & $34(34 \%)$ \\
\hline Spontaneous vaginal & $13(13 \%)$ \\
\hline LSCS & $53(53 \%)$ \\
\hline Instrumental delivery & $00(0 \%)$ \\
\hline
\end{tabular}

Table 4: Birth weight distribution.

\begin{tabular}{|l|l|}
\hline Baby weight $(\mathrm{kg})$ & No. of cases \\
\hline $\mathbf{1}$.5 & $20(20 \%)$ \\
\hline $\mathbf{1 . 5 - 2 . 0}$ & $26(26 \%)$ \\
\hline $\mathbf{2 . 1 - 2 . 5}$ & $31(31 \%)$ \\
\hline $\mathbf{2 . 6 - 3 . 0}$ & $19(19 \%)$ \\
\hline $\mathbf{> 3 . 0}$ & $04(4 \%)$ \\
\hline
\end{tabular}

The majority (50\%) of cases in this study were primigravida, $25 \%$ of cases were of the second gravida, $17 \%$ were the third gravida, $4 \%$ were the fourth gravida, $1 \%$ was the fifth gravida and $3 \%$ were the sixth gravida. (Table 2)

In this study at the time of presentation, $42 \%$ of cases were having a gestational age of 37 to 39 weeks, $22 \%$ had 34 to 36 weeks, $18 \%$ had 31 to 33 weeks, $15 \%$ had more than 39 weeks and $3 \%$ had 28 to 30 weeks.

In my study, the most common risk factor was hypertension in pregnancy $(38 \%)$ followed by intrauterine growth retardation in $29 \%$, Doppler changes in $24 \%$, post dates in $9 \%$, and $30 \%$ of cases had no risk factors.

Table 5: Relation between NICU admission and doppler findings.

\begin{tabular}{|llll|}
\hline $\begin{array}{l}\text { NICU } \\
\text { admission }\end{array}$ & Yes & No & Total \\
\hline $\begin{array}{l}\text { Normal } \\
\text { Doppler }\end{array}$ & $43(66 \%)$ & $34(44 \%)$ & $77(77 \%)$ \\
\hline $\begin{array}{l}\text { Abnormal } \\
\text { Doppler }\end{array}$ & $21(91 \%)$ & $02(09 \%)$ & $23(23 \%)$ \\
\hline
\end{tabular}

Table 6: Prevalence of anomalies.

\begin{tabular}{|ll|}
\hline Anomaly & No. of cases \\
\hline Cleft lip and palate & $02(2 \%)$ \\
\hline Multicystic kidney disease & $02(2 \%)$ \\
\hline B/L renal agenesis & $01(1 \%)$ \\
\hline No anomaly & $95(95 \%)$ \\
\hline
\end{tabular}

Table 7: Relation between NST and mode of delivery.

\begin{tabular}{|llll|}
\hline NST & $\begin{array}{l}\text { Vaginal } \\
\text { delivery }\end{array}$ & Caesarean & Total \\
\hline Reactive & $38(55 \%)$ & $31(45 \%)$ & $69(69 \%)$ \\
\hline $\begin{array}{l}\text { Non- } \\
\text { reactive }\end{array}$ & $12(39 \%)$ & $19(61 \%)$ & $31(31 \%)$ \\
\hline
\end{tabular}

Table 8: Relation between Doppler and mode of delivery.

\begin{tabular}{|llll|}
\hline $\begin{array}{l}\text { Doppler } \\
\text { Study }\end{array}$ & $\begin{array}{l}\text { Normal } \\
\text { vaginal } \\
\text { delivery }\end{array}$ & Caesarean & Total \\
\hline Normal & $34(44 \%)$ & $43(66 \%)$ & $77(77 \%)$ \\
\hline Abnormal & $14(61 \%)$ & $09(39 \%)$ & $23(23 \%)$ \\
\hline
\end{tabular}

In my study $31 \%$ of the patients had $4 \mathrm{~cm}$ of AFI, $27 \%$ had $2 \mathrm{~cm}$ of AFI, $21 \%$ had $3 \mathrm{~cm}$ of AFI, $14 \%$ had 0 of AFI, $4 \%$ had $2 \mathrm{~cm}$ of AFI, $3 \%$ had $5 \mathrm{~cm}$ of AFI.

In the study majority of the cases $(69 \%)$ had a reactive nonstress test.

In this study the most common doppler abnormality was reduced diastolic flow in uterine artery in $12 \%$ cases, $6 \%$ cases showed absent diastolic flow in uterine artery, $4 \%$ had brain sparing effect and $1 \%$ showed early diastolic notch while $77 \%$ cases had no abnormality in doppler.

The majority, $53 \%$ of the cases underwent LSCS for delivery, $34 \%$ underwent induced vaginal delivery and 
$13 \%$ had a spontaneous vaginal delivery. There was no instrumental delivery in our study. (Table 3)

Of all the cases that underwent LSCS, severe oligohydramnios was the reason in $42 \%$ cases, previous CS in $13 \%$, Fetal distress in $11 \%$, doppler changes in $9 \%$, breech and IUGR both had $7.5 \%$ of prevalence, failed induction in $6 \%$, and placenta previa had least $4 \%$ of prevalence.

In our study, $4 \%$ of cases had Postpartum Haemorrhage, of which 2 were primigravida and 2 were multigravida. Otherwise, there were no maternal complications in $96 \%$ of cases.

In this study, the birth weight of the baby was between 2.1 to $2.5 \mathrm{~kg}$ in $31 \%$ cases, 1.5 to $2 \mathrm{~kg}$ in $26 \%$ cases, $<1.5 \mathrm{~kg}$ in $20 \%$ cases, 2.6 to $3.0 \mathrm{~kg}$ in $19 \%$ cases and $>3 \mathrm{~kg}$ in 45 cases. (Table 4)

A total $73 \%$ of neonates had APGAR scores between 7 to 9 and $27 \%$ had between 4 to 6 .

In our study, we observed that from the $23 \%$ cases with abnormal Doppler findings $91 \%$ required NICU admission, while of the $77 \%$ cases having normal doppler had only $66 \%$ NICU admission. (Table 5)

In the study we encountered 5 anomalies in neonates at childbirth, 2 had cleft lip and palate, 2 had multicystic kidney disease, one had B/L renal agenesis. (Table 6)

Of the $50 \%$ primigravida, the incidence of vaginal delivery was $24 \%$ and caesarean section was $52 \%$. While from the $50 \%$ multigravida there was $50 \%$ incidence for both vaginal and caesarean section.

Operative morbidity was significantly higher in NST nonreactive $(61 \%)$ group than NST reactive $(45 \%)$ group. $55 \%$ of patients with reactive NST delivered vaginally. (Table 7)

In our study, $23 \%$ of cases had abnormal doppler findings of which $39 \%$ had to undergo caesarean section and $61 \%$ had vaginal delivery. $77 \%$ had normal doppler of which $66 \%$ had caesarean section and $44 \%$ had vaginal delivery. (Table 8)

We noticed in our study significantly higher NICU admission in non-reactive NST cases $93 \%$ compared to reactive cases which had $45 \%$ NICU admission. We noted higher mortality in neonates with abnormal doppler amounting to $61 \%$ of the 23 cases with abnormal doppler findings compared to only $19 \%$ neonatal deaths from the 77 cases with normal doppler. In our study, there was $13 \%$ neonatal mortality in cases who underwent elective caesarean section, while there was $44 \%$ and $54 \%$ neonatal mortality in induced vaginal and spontaneous vaginal delivery respectively. Neonatal morbidity was significantly higher in the non-reactive group having 52\% neonatal death compared to the reactive NST group $19 \%$.

\section{DISCUSSION}

\section{Impact of age}

Out of 100 patients recruited in our study maximum number of patients $94 \%$ were in the 20-30 years age group with a mean age of 24.6 years. In Bhat et al the maximum number of patients $85 \%$ were $20-30$ years of age. ${ }^{9}$ In Modi et al $90 \%$ of cases were between 20-30years. ${ }^{10}$ In Casey et al, the mean maternal age was 23.9 years. ${ }^{11}$ In Radhamani et al most of the patients $(54.6 \%)$ were between $37-40$ years of age. ${ }^{12}$ Of the $94 \%$ in our study $45 \%$ were delivered vaginally and $49 \%$ had to undergo caesarean section, in Bhat et al, from the $85 \%$, vaginal delivery occurred in $65 \%$ and caesarean section in 35\%, in Modi et al from the $90 \%$ caesarean section was done in $44 \%$ cases..$^{9,10}$

\section{Impact of gravida}

The incidence of oligohydramnios was $50 \%$ in primigravida and $50 \%$ in multigravida. Bhat et al showed an incidence of $54 \%$ in primigravida and $46 \%$ in multigravida. ${ }^{9}$ In Donald $\mathrm{D}$ et al, the incidence of oligohydramnios was $60 \%$ in primigravida. ${ }^{13}$

\section{Gravida and operative morbidity}

The incidence of caesarean section was more in primigravida in both our study (52\%) and Bhat et al study $(44.5 \%)$ compared to multigravida cases $50 \%$ and $30.5 \%$ respectively. ${ }^{9}$ In Modi et al the incidence on caesarean in primigravida was $56 \%$ and in multigravida was $27 \% .^{10}$

\section{Doppler findings and its impact}

$23 \%$ of cases in our study had abnormal doppler findings of which $39 \%$ had to undergo caesarean section. While in Bhat et al study $14 \%$ of cases had abnormal doppler findings of which $71 \%$ underwent caesarean section. ${ }^{9}$ In Modi et al $7 \%$ had abnormal doppler findings of which $86 \%$ underwent caesarean section. ${ }^{10}$ In Weiss et al and Young et al, it was $71 \%$ and $69.7 \%$ respectively. ${ }^{14,15}$ Thus, the operative morbidity was much lower in our study for cases with abnormal doppler findings.

\section{NST and its impact}

In our study due to non-reactive NST which was $31 \%$ of total cases $61 \%$ of cases underwent caesarean section. In Bhat et al study from $38 \%$ of non-reactive NST cases $74 \%$ of cases underwent caesarean section. ${ }^{9}$ The operative morbidity was lower in our study for this group. The caesarean section was done in $73.6 \%$ of patients with nonreactive NST in the Charu Jandial study. ${ }^{16}$ 


\section{Operative morbidity}

The mode of delivery for the majority of cases $53 \%$ in our study was caesarean section and $47 \%$ underwent vaginal delivery and in Bhat et al study $62 \%$ cases underwent vaginal delivery and $38 \%$ by caesarean. ${ }^{9}$ Sir Gangaram Hospital study shows $68 \%$ vaginal deliveries and $32 \%$ caesarean section. ${ }^{17}$ Manzanares et al shows $84 \%$ vaginal deliveries and $16 \%$ by caesarean section. ${ }^{18}$ Bansal et al show $47 \%$ caesarean section. ${ }^{19}$ Golan et al found that, the caesarean section was performed in $35.2 \%$ of pregnancies. $^{20}$

\section{Operative cause}

The major indication for caesarean in our study was oligohydramnios amounting to $42 \%$ of cases and fetal distress amounting to only $11 \%$ cases. In Bhat et al study fetal distress was the major cause $66 \%$ and oligohydramnios amounting to only $13 \%$ of the cases. ${ }^{9}$ In Modi et al fetal distress caused caesarean in $21 \%$ of cases and oligohydramnios in $9 \%$ of cases Fetal distress was the major indication for caesarean section in these studies as well, Radhamani et al 31\%, Bachhav et al 24\%, Nazlima et al $58 \%$, Jandial et al $42 \% .^{10,12,16,21,22}$

\section{Impact on birth weight}

The mean baby weight in our study was $2.1 \mathrm{~kg}$ with $77 \%$ having $<2.5 \mathrm{~kg}$ birth weight. Bhat et al study had a mean baby weight of $2.3 \mathrm{~kg}$ with only $36 \%$ having $<2.5 \mathrm{~kg}$ birth weight. ${ }^{9}$ In Radhamani et al $17.7 \%$ had $<2.5 \mathrm{~kg}$ birth weight and $64 \%$ in Bachhav et al and $65.3 \%$ in Nazlima et al. ${ }^{12,21,22}$ The incidence of low-birth-weight babies are higher in Oligohydramnios except in post maturity where the babies may have average birth weight, suggesting a correlation of IUGR with oligohydramnios.

\section{Liqour color}

In our study, the liquor was clear in $80 \%$ and meconiumstained in $20 \%$. In Radhamani et al $81.5 \%$ clear liquor and $18.5 \%$ had meconium-stained liquor. ${ }^{12}$

\section{Impact on APGAR score}

In our study, $27 \%$ of cases had APGAR $<7$. Bhat et al study, Modi et al study and Manning et al study had $15 \%$ cases with APGAR <7..$^{9,10,23}$ In Sariya et al it was $38 \%$. In Bansal et al it was $17.5 \%{ }^{19,24}$

\section{Impact on NICU requirement}

In our study, $64 \%$ of neonates required NICU which was much higher than Bhat et al study which had only $28 \%$ NICU admissions. ${ }^{9}$ In Jhonson et al $20 \%$ of babies had NICU admission, in Manning et al and Sariya et al, $43 \%$ and $88.88 \%$ respectively. Bansal et al had $36 \%$ NICU admissions. ${ }^{19,23-25}$

\section{Death of the child}

Neonatal death was higher in our study amounting to $29 \%$ cases than Bhat et al study which had 5\% neonatal deaths and Golan et al show $6.3 \%$ neonatal death. Bansal et al study had $15 \%$, Casey had $6.3 \%$ and Modi et al had $4 \%$ perinatal death. ${ }^{9-11,19,20}$

\section{Congenital anomalies}

Birth anomalies in our study was $5 \%$ while in Bansal et al it was 9\%. Manning et al had 13\%, Casey had $10 \%$ and Modi et al had $1 \%$ congenital abnormalities. ${ }^{10,11,19,23}$

Oligohydramnios is a frequent occurrence and demands intensive fetal surveillance and proper antepartum and intrapartum care. Oligohydramnios is a frequent finding in pregnancy involving IUGR, PIH, and pregnancy beyond 40 weeks of gestation. Amniotic fluid volume is a predictor of fetal tolerance in labour and its decrease is associated with an increased risk of abnormal heart rate and meconium-stained fluid. Due to intrapartum complications and a high rate of perinatal morbidity and mortality, rates of caesarean section are rising, but the decision between vaginal delivery and caesarean section should be well balanced so that unnecessary maternal morbidity can be prevented and on the other side timely intervention can reduce perinatal morbidity and mortality.

\section{CONCLUSION}

Oligohydramnios is being detected more often these days due to routinely performed obstetric USG. Oligohydramnios is one of the indicators of poor perinatal outcome. It is associated with fetal heart rate abnormalities, meconium staining of amniotic fluid, umbilical cord compression, poor tolerance of labour, low APGAR score and fetal acidosis. Pregnancy-induced hypertension; post-dated pregnancies are the commonest causes of reduced amniotic fluid during the third trimester of pregnancy. Oligohydramnios with reactive NST is associated with a good prognosis. Oligohydramnios with nonreactive NST needs careful monitoring and results in early delivery, increased incidence of caesarean delivery for fetal distress, NICU admission, low APGAR score at 5 mins, and neonatal death. The mode of delivery depends on the severity of oligohydramnios and the status of fetal wellbeing. Caesarean section is mostly required for cases with anhydramnios with intrapartum fetal heart abnormalities. Babies are relatively more prone to certain complications like intrapartum fetal distress, MAS, and birth asphyxia. Oligohydramnios associated with IUGR carries a poor perinatal outcome (increased neonatal death, NICU admission, increased rate of caesarean section for fetal distress, very low birth weight). Hence, they need good neonatal care. From this study, we conclude that oligohydramnios is a high-risk pregnancy and proper antepartum care, intensive fetal surveillance and intrapartum care are required in a patient with oligohydramnios. Every case of oligohydramnios needs 
careful antenatal evaluation, parental counselling, individualization, decisions regarding time and mode of delivery. Continuous intrapartum fetal monitoring and good neonatal care are necessary for a better perinatal outcome.

Funding: No funding sources

Conflict of interest: None declared

Ethical approval: The study was approved by the Institutional Ethics Committee

\section{REFERENCES}

1. Moore TR. Amniotic fluid dynamics reflect fetal and maternal health and disease. Obstet Gynecol. 2010;116:759-65.

2. Hashimoto BE, Kramer DJ, Brennan L. Amniotic fluid volume: fluid dynamics and measurement technique. Semin Ultrasound CT MR. 1993;14:40-55.

3. Albert SP, Myoung AO, Jeffrey PP. Intrapartum amniotic fluid volume at term. J Reprod Med. 1990;35:719-23.

4. Dasari P, Niveditta G, Raghavan S. The maximal vertical pocket and amniotic fluid index in predicting fetal distress in prolonged pregnancy. Int J Gynaecol Obstet. 2007;96(2):89-93.

5. Sultana S, Akbar Khan MN, Khanum Akhtar KA, Aslam M. Low amniotic fluid index in high-risk pregnancy and poor apgar score at birth. J Coll Physicians Surg Pak. 2008;18(10):630-4.

6. Rainford M, Adair R, Scialli AR, Ghidini A, Spong CY. Amniotic fluid index in the uncomplicated term pregnancy. Prediction of outcome. J Reprod Med. 2001;46(6):589-92.

7. Phelan JP, Smith CV, Broussard P, Small M. Amniotic fluid volume assessment using the fourquadrant technique in the pregnancy at 36-42 weeks gestation. J Reprod Med. 1987;32(7):540-2.

8. Marino T. Ultrasound abnormalities of the amniotic fluid, membranes, umbilical cord, and placenta. Obstet Gynecol Clin N Am. 2004;31:177-200.

9. Bhat S, Kulkarni V. Study of effect of oligohydramnios on maternal and fetal outcome. Int J Med and Dent Sci. 2015;4(1):582-8.

10. Modi JY. Int J Reprod Contracept Obstet Gynecol. 2016;5(11):4037-40.

11. Casey BM, McIntire DD, Bloom SL, Lucas MJ, Santos R, Twickler DM et al. Pregnancy outcomes after antepartum diagnosis of oligohydramnios at or beyond 34 weeks' gestation. Am J Obstet Gynecol. 2000;182(4):909-12.

12. Radhamani S, Babitha. A clinical study of fetomaternal outcome in pregnancies with oligohydramnios. Int $\mathbf{J}$ Reprod Contracept Obstet Gynecol. 2017;6:868-71.

13. Petrozella LN, Dashe JS, McIntire DD, Leveno KJ. Clinical Significance of Borderline Amniotic Fluid Index and Oligohydramnios in Preterm Pregnancy. Obstetrics \& Gynecology. 2011;117(2 Pt 1):338-42.

14. Hitschold T. Weiss in the umbilical artery. Z Geburtshilfe Perinatol. 1989;193(1):42-6.

15. Kwon JY, Kwon HS, Kim YH, Park YW. Abnormal Doppler Velocimetry is related to adverse perinatal outcome for borderline amniotic fluid index during third trimester. J Obstet Gynecol Res. 2006:32(6):545-49.

16. Jandial C, Gupta S, Sharma S, Gupta M. Perinatal Outcome After Antepartum Diagnosis of Oligohydramnios at or Beyond 34 Weeks of Gestation. JK science. 2007;9(4):213-14.

17. Umber A. Perinatal Outcome in Pregnancies Complicated by Isolated Oligohydramnios at Term. Annals. 2009;15:35-7.

18. Manzanares S, Carrillo MP, GonzálezPerán E, Puertas A, Montoya F. Isolated oligohydramnios in term pregnancy as an indication for induction of labor. $\mathbf{J}$ Matern Neonatal Med. 2007;20(3):221-4.

19. Bansal D, Deodhar P. A Clinical Study of Maternal and Perinatal Outcome in Oligohydramnios. J Res Med Den Sci. 2015;3(4):312-6.

20. Golan A, Lin G, Evron S, Arieli S, Niv D, David MP. Oligohydramnios: maternal complications and fetal outcome in 145 cases. Gynecol Obstet Invest. 1994;37(2):91-5.

21. Bachhav AA, Waiker M. Low amniotic index at term as a predictor of adverse perinatal outcome. J Obstet Gynaecol India. 2014;64(2):120-3.

22. Nazlima N, Fathima B. Oligohydromnios at third trimester and perinatal outcome. Bangladesh $\mathrm{J}$ Med sci. 2012;11(1):33-6.

23. Manning FA, Harmon CR, Morrison I. Fetal assessment based on fetal biophysical profile scoring. An analysis of perinatal mortality and morbidity. American Journal of obstetrics and gynecology. 1991;162:703-9.

24. Sriya R, Singhai S. Perinatal outcome in patients with amniotic fluid index $<5 \mathrm{~cm}$. J Obstet Gynaecol. 2001;51:98-100.

25. Johnson JM, Chauhan SP, Ennen CS, Niederhauser A, Magann EF. A comparison of 3 criteria of oligohydramnios in identifying peripartum complications: a secondary analysis. Am J Obstet Gynecol. 2007;197(2):207.e1-7.

Cite this article as: Prajapati S, Johar S. Fetomaternal outcome of oligohydramnios in tertiary care hospital. Int J Reprod Contracept Obstet Gynecol 2021;10:4101-6. 